\title{
Correction to: Production and Characterization of Boride and Carbide Layers on AISI 15B30 Steel
}

Rafael Magalhães Triani (D), Lucas Fuscaldi De Assis Gomes, Amadeu Lombardi Neto, George Edward Totten, and Luiz Carlos Casteletti

\section{Correction to: \\ JMEPEG \\ https://doi.org/10.1007/s11665-020-04698-w}

The following correction should be noted to this article:

In the introduction, "In order to increase steels hardenability, additions of boron between 0.0003 up to $0.003 \mathrm{wt} \%$ improve fracture susceptibility and distortions during cooling" should read "To increase the hardenability of steels, additions of boron between 0.0003 and 0.003 wt.\% decrease fracture susceptibility and distortions during cooling."

Publisher's Note Springer Nature remains neutral with regard to jurisdictional claims in published maps and institutional affiliations

The original article can be found online at https://doi.org/10.1007/ s11665-020-04698-w.

Rafael Magalhães Triani, Lucas Fuscaldi De Assis Gomes, and Luiz Carlos Casteletti, Materials Engineering Department, São Carlos School of Engineering, University of São Paulo, São Carlos, São Paulo, Brazil; Amadeu Lombardi Neto, Department of Materials, Universidade Tecnológica Federal do Paraná, Londrina, Paraná, Brazil; and George Edward Totten, Department of Mechanical and Materials Engineering, Portland State University, Portland, OR. Contact e-mail: rmtriani@gmail.com. 